\title{
Medical Tourism in Lebanon: An Analysis of Tourism Flows
}

\author{
By Viana Hassan*
}

\begin{abstract}
Medical tourism is defined as the travelling activities of patients seeking low-cost treatment in third world countries. Lately, this field of tourism has been growing very fast due the specialization of medical agencies, hospitals and medical professionals. In Lebanon, medical tourism could evolve to account for an important share of the regional economy, as only in 2014, it has generated growth worth of $\$ 1.2$ billion. In the recent years, several factors have been contributing in medical tourism's progress such as medical professionalism, the media and the attractive landscape. Especially the role of media is crucial for the development of this activity in Lebanon, as through this channel, the operation of medical centers and hospitals as well as the advantages and disadvantages of medical tourism could get in the center of public discourse. The main objective of the present study is to present and analyze the flows (both inflows and outflows) of medical tourism in Lebanon.
\end{abstract}

Keywords: Lebanon, Medical tourism, Tourism flow

\section{Introduction}

Medical tourism is a growing international field of economy activity that generates up to 55 billion dollars on average annually. Among the countries of the Middle East, Lebanon appears to be attracting medical tourism the most; $10 \%$ of the tourists coming to Lebanon, identify receiving medical treatment as the main purpose of their visit (Chardon 2010). The number of these tourists is calculated at approximately 10,000-15,000 per year; 90\% of them come from the Middle East and the remaining $10 \%$ are Europeans or Americans ${ }^{1}$. Evidently, the development of medical tourism activities could be an asset for the Lebanese economy, entertaining the prospect of diversification of its activities. This attractiveness could be further supported by the media (Chardon 2010), which could display and promote the quality of hospitalization services, the high standards of the medical services, etc.

However, medical tourism in Lebanon is a mainly uncharted economic area. The existence of just a few articles, references or books in relation to this theme is a strong indication the fact that the benefits of medical tourism for national economy are neglected. Articles published on the internet and in the press are mainly about aesthetic tourism with medical tourism not receiving much attention in general.

\footnotetext{
${ }^{*}$ Lecturer, Lebanese International University, Lebanon.

${ }^{1}$ Personal communications with N. Sardouk, Director of Ministry of Tourism, in 2011.
} 
However, after extensive research, we managed to retrieve a report, written in 2007 ESA by Dr. Jean El Hage, neurosurgeon at the Hospital of the Sacred Heart, analyzing medical tourism in the Lebanon.

On this ground and given the importance of this kind of touristic activities for economic development, it is considered essential to fill the existing gap by examining whether Lebanon is really attractive for medical tourism, analyzing the specific characteristics and background of medical tourists and finally, identifying the reasons for which they visit Lebanon. Therefore, we will attempt to demonstrate that Lebanon is indeed an attractive country for medical tourism, analyze medical tourist flows (both outbound and inbound) and finally, understand the main motivation driving medical tourism.

Although medical tourism is proven to be associated with significant gains, its effects are not always economical. Looking at the non-pecuniary aspects of medical tourism's multidimensional impact, there may also emerge risks such as complications arising from medical interventions and postoperative problems caused by pharmaceuticals (Bauer 2008, Jeevan 2008, Vaillant 2010).

The present research project was conducted in Beirut, the economic center of Lebanon, where the largest share of tourism investments is concentrated and which remains the health center of the country, as many university hospitals, medical centers, specialist clinic, etc. are located there. The majority of the main secondary and tertiary activities of the whole national economy are practiced in Beirut and it also holds the second place in the region of Levant, after Dubai, in the field of modernization and specialization of medical activities.

\section{Methodology}

In Lebanon, there is a treaty about medical tourism where some articles discussing the advantages of this type of activity can be found. However, there still exists a lack of studies centered in the analysis of tourist flows; a theoretical concept of the evaluation of the movements of tourists in a specific geographic area, ranging from the local to the global level. In the present paper, we will implement the following research methods in order to study tourist flows:

- Collection of statistical data from the main ministries involved in this domain (tourism, health and finance ministries) as well as from the national airline company, Middle East Airlines (MEA).

- Questionnaires addressed to different key players of medical tourism in order to gain deep understanding of this phenomenon, its progress, and its potential impact on general tourism development.

- Spatial analysis of tourist flows, based on two concepts: attractiveness of medical facilities and the specific characteristics of Lebanon which make it an ideal country for medical tourism. 


\section{Inflows Analysis}

As a first step, it is considered necessary to study the inflow of medical tourists. This analysis should enable us to assess the overall attractiveness of Lebanon to foreign tourists. For this purpose, we have used statistics obtained from the Ministry of Tourism for the years 2007-2012 which give us a general idea regarding the evolution of this type of tourism and the tourists' background (e.g. the country of origin of the patients).

\section{Evolution of Inflow}

Table 1, showing hard figures on the total number of medical tourists from 2007 to 2011 in Lebanon, allows us to observe an average growth of $5.3 \%$ in the total number of medical tourists during this period. For the period between 2007 and 2009, the number of total tourists appears to increase with time, reaching to a peak in 2009. Nonetheless, after reaching this maximum level, the average growth rate became negative $(-11.63 \%)$ for the period 20092010 , experiencing a significant drop of 22 percentage points, which only started to get reversed in 2011.

Table 1. Annual Growth Rate of Medical Tourists

\begin{tabular}{|c|c|c|c|}
\hline & $\begin{array}{c}\text { Total Medical Tourists } \\
\text { (Reference 2010) }\end{array}$ & $\begin{array}{c}\text { Index } \\
\text { (Reference 2012) }\end{array}$ & Average Annual Growth Rate \\
\hline $\mathbf{2 0 0 7}$ & 53,107 & 108 & $-1.65 \%$ \\
\hline $\mathbf{2 0 0 8}$ & 64,839 & 75 & $-6.93 \%$ \\
\hline $\mathbf{2 0 0 9}$ & 70,103 & 1431 & $-11.63 \%$ \\
\hline $\mathbf{2 0 1 0}$ & 32,853 & 67 & $22 \%$ \\
\hline $\mathbf{2 0 1 1}$ & 38,997 & 0.7 & $25 \%$ \\
\hline $\mathbf{2 0 1 2}$ & 48,958 & 100 & $5.35 \%$ \\
\hline Average & & & \\
\hline
\end{tabular}

Source: Ministry of Tourism, 2012.

Table 2 representing raw values of the number of tourists, also confirms that there was indeed a growth in the total number of tourists; from 2007 to $2009,826,928$ additional visitors (approximately more than $45 \%$ of the general share of tourists) visited Lebanon. After 2009 the inflow of medical tourists begins its downturn to reach the number of 1,178,959 tourists in 2012 (or 64 percentage points smaller share of medical tourists compared to 2009). Nevertheless, it should be noted that the total number of tourists, including medical tourists, in 2010 is higher than that of 2007. In comparison, for the period 2007-2009, the number of medical tourists follows the general upward trend of the total inflow of tourists in general. After 2010, medical tourism does not follow the same trends as regular tourism, as after reaching its minimum level in 2010, the number of medical tourists is again ascending, but in levels well below that of the years 2007-2009. After this comprehensive comparative analysis of inflows, the next step would be to the determination of 
medical tourists' countries of origin, regarded as an important proxy of their socioeconomic background.

Table 2. Evolution of the Number of Medical Tourists to Lebanon

\begin{tabular}{|c|c|c|c|}
\hline & Total tourists & Total medical tourists & \% medical tourists \\
\hline $\mathbf{2 0 0 7}$ & $1,017,072$ & 53,107 & $5.2 \%$ \\
\hline $\mathbf{2 0 0 8}$ & $1,332,551$ & 64,839 & $4.9 \%$ \\
\hline $\mathbf{2 0 0 9}$ & $1,844,000$ & 70,103 & $3.8 \%$ \\
\hline $\mathbf{2 0 1 0}$ & $1,492,133$ & 32,853 & $2.2 \%$ \\
\hline $\mathbf{2 0 1 1}$ & $1,655,051$ & 38,997 & $2.4 \%$ \\
\hline $\mathbf{2 0 1 2}$ & $1,178,959$ & 48,958 & $4.2 \%$ \\
\hline
\end{tabular}

Source: Ministry of Tourism, 2012.

\section{Origin of Inflows}

What we are interested to examine is the countries where the medical tourists visiting Lebanon come from as well as the share of its country in the total number of medical tourists. The objective here is to identify which are the nationalities who prefer Lebanon for receiving their medical treatment despite the competition of neighboring countries (Jordan, Syria, Tunisia, UAE) offering the "Surgery Vacations" packages, including the cost of the surgery, the accommodation and the transportation through travel agencies and websites (Figure 1).

Figure 1. The Average Flow of Medical Tourists, 2007-2012

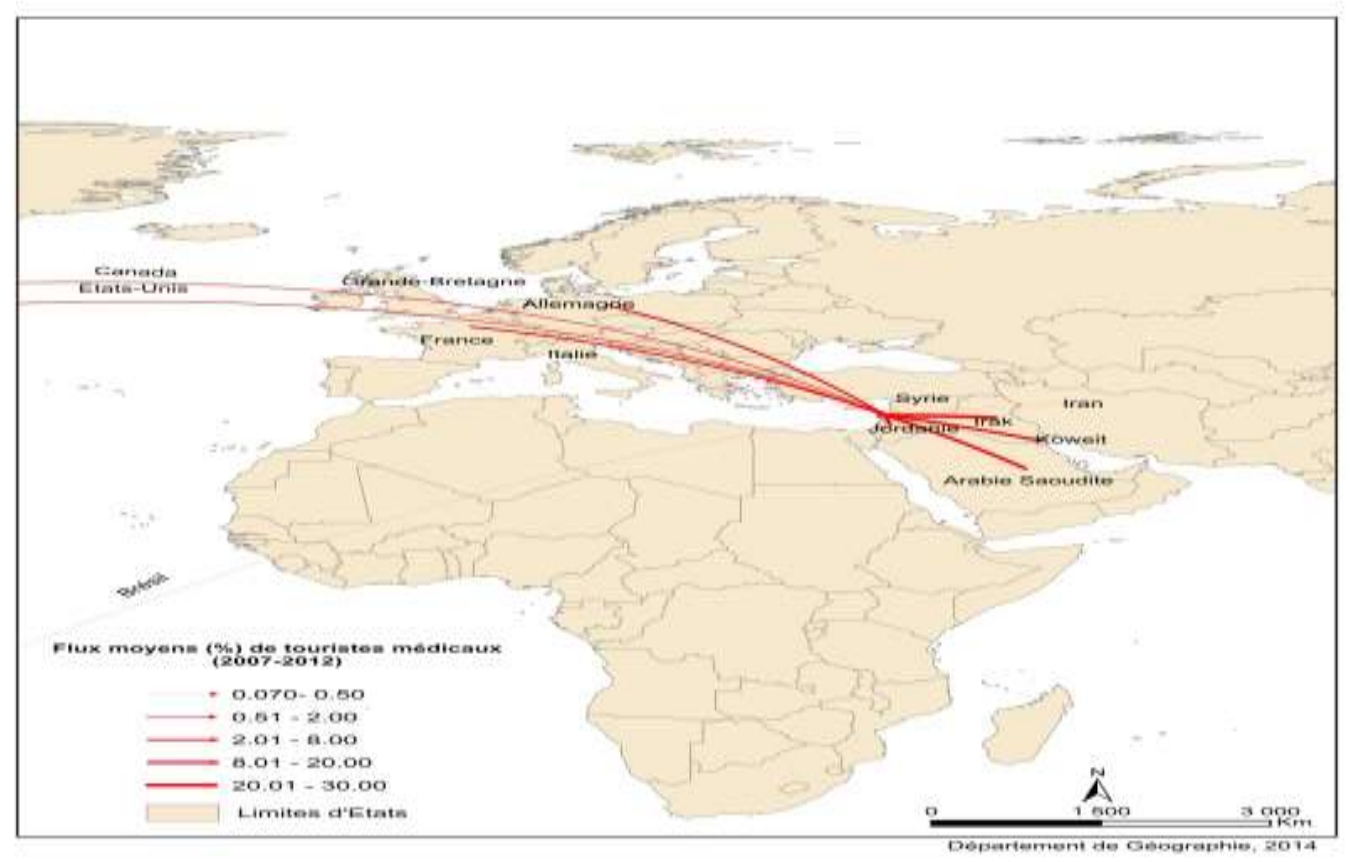

Source: Geography Department USJ, 2014. 
Table 3. Average Flow of Medical Tourists by Country, 2007-2012

\begin{tabular}{|l|c|}
\hline & Average percentage (2007-2012) \\
\hline Iraq & $29.65 \%$ \\
\hline Saudi Arabia & $17.27 \%$ \\
\hline Syria & $14.42 \%$ \\
\hline Kuwait & $11.9 \%$ \\
\hline France & $7.91 \%$ \\
\hline Germany & $5.49 \%$ \\
\hline
\end{tabular}

Source: Geography Department USJ, 2014.

With respect to average flow of medical tourists for the period of 20072012, it is noted that the majority of the medical tourists come from the Arab countries. Iraq has a clear lead with (29.65\%), followed by Saudi Arabia $(17.27 \%)$, Syria (14.42\%) and finally, Kuwait (11.9\%). The European tourists mostly come from France (7.91\%) and Germany (5.49\%) (Table 3).

Table 4. Spatial Analysis of Medical Tourists Flow by Country, 2007-2012

\begin{tabular}{|l|c|c|c|c|c|c|}
\hline \multirow{2}{*}{ Jordan } & \multicolumn{7}{|c|}{ Spatial analysis } \\
\cline { 2 - 7 } & $\mathbf{2 0 0 7}$ & $\mathbf{2 0 0 8}$ & $\mathbf{2 0 0 9}$ & $\mathbf{2 0 1 0}$ & $\mathbf{2 0 1 1}$ & $\mathbf{2 0 1 2}$ \\
\hline Saudi Arabia & 1.1731848 & 0.947442 & 0.925731 & 1.610494 & 0.403918 & 1.610494 \\
\hline Kuwait & 0.926101 & 0.901028 & 0.873836 & 1.567888 & 0.948141 & 1.567888 \\
\hline Iraq & 0.617323 & 0.638481 & 0.684768 & 1.695979 & 1.929226 & 1.695979 \\
\hline France & 1.067961 & 0.983269 & 0.99529 & 0.212379 & 1.073511 & 2.123789 \\
\hline Germany & 0.441451 & 0.798176 & 0.970945 & 1.96242 & 0.939842 & 1.96242 \\
\hline Britain & 0.234664 & 1.025086 & 0.983667 & 1.896674 & 0.93208 & 1.896674 \\
\hline Italy & 0.451151 & 0.685291 & 1.031532 & 1.896148 & 1.117069 & 1.896148 \\
\hline Iran & 1.025705 & 0.823311 & 0.831422 & 1.75754 & 0.698414 & 1.75754 \\
\hline USA & 0.283035 & 0.692443 & 0.950883 & 1.963387 & 1.36581 & 1.963387 \\
\hline Canada & 0.370924 & 0.779109 & 0.913036 & 1.889857 & 1.163687 & 2.044482 \\
\hline Brazil & 1.072028 & 0.943908 & 0.812122 & 1.472996 & 0.948942 & 1.472996 \\
\hline Syria & 1.686833 & 1.67003 & 1.577555 & 0.003304 & 0.003809 & 0.004348 \\
\hline Others & 0.923135 & 0.705696 & 0.799231 & 1.580365 & 0.993744 & 2.050779 \\
\hline
\end{tabular}

Source: Geography Department USJ, 2014.

A fine analysis of the preferential programs allows us to confirm that in the period between 2007 and 2009, Syria and Saudi Arabia were the countries mostly providing Lebanon with medical tourists. Despite the country's small size and population, tourists from Jordan also appear to account for an important share of medical tourism inflows in 2007, 2010 and 2012. Compared to other Arab countries, Jordan has established preferential relations with Lebanon. The same conclusion also holds for the case of Brazil. In the European field, France appeared to significantly support the Lebanese medical tourism sector in 2007, 2011 and 2012 (Table 4).

Observing the share of each country of origin in the total number of medical tourists, it is evident that medical tourists who used to prefer Lebanon for their medical needs, from all countries except Syria, continued to travel to 
Lebanon for treatment in 2010 and 2012. In addition, in 2010, all these countries appeared to hold even stronger preferences for Lebanon. In the same year, the majority of tourists came from Germany, the United States and the United Kingdom, followed by Italy and Iraq. The inflow of tourists from Saudi Arabia, France, and Syria had decreased (Table 4).

In 2011, the number of tourists coming from France, Canada, and the United States continued to rise, while in the case of Arab countries, only the share of tourists coming from Iraq increased rapidly. Tourists from the rest Arab countries, namely Jordan, Kuwait and Saudi Arabia decreased. Finally, in 2012, a lot of international medical tourists arrived in Lebanon from European and neighboring countries. The distribution of medical tourists choosing Lebanon for their treatment across different countries of origin is the following in 2012: French (2.12), Germans (1.96), British (1.89), Italians (1.89), followed by Canadians (2.04) and Americans (1.96). Among the countries of the Middle East, Saudi Arabia ranked first followed by Iraq, Kuwait and Jordan (Table 4).

\section{Reasons}

The conclusion to be reached is that the majority of tourists seeking medical treatment in Lebanon come mainly from its neighboring countries which have also experienced an evolution in the provision of health-care services. The research question arising here concerns the specific reasons for which people choose to travel to Lebanon, reflecting the mechanisms driving this development.

\section{Medical Insurances}

In Europe and America, the provision of treatment is financed and supported by public welfare policies, as the regime of social security in France. Nevertheless, such types of insurance do not always cover the areas of dentistry and esthetics, with treatment falling into these categories often considered as being associated to exorbitant costs.

To better understand this aspect, let us consider the example of the regular price of a metal-ceramic crown in France, amounting to around $850 €$. In the context of the public social security scheme, $70 \%$ of the price is supposed to be refunded. However, the baseline price, on the basis of which the refund is calculated, is defined by a relevant social security index at the level of $107.5 €$. Consequently, the final refund that the patient receives is less than $10 \%$ of the actual price ${ }^{1}$.

\section{Health Sector}

According to the Union of the Lebanese hospitals, 165 hospitals, of both short and medium stay, 135 of which being private and 30 public, were located in Lebanon in 2011, having a maximum capacity of 15,345 beds. More than half $(51 \%)$ of these hospitals were located in the regions of Mount Lebanon

\footnotetext{
${ }^{1}$ http://implant-prothese-dentaire.comprendrechoisir.com/comprendre/prix-prothèse-dentaire.
} 
and Beirut. On 11,505 doctors and Surgeons provide health-care services today in Lebanon, $85 \%$ of them specializing in one field and the rest $15 \%$ holding more than one specialization. In addition, nearly half of them have graduated from international universities: $37 \%$ of them have graduated from Central European universities, mainly in France and Germany, and also from Eastern European universities specializing in the dental field, mainly in Bulgaria and Romania, while $11 \%$ have obtained degrees from American or Canadian universities $35 \%$ of the active doctors are Lebanese universities graduates (Boutros 2010). The Lebanese advanced human capital involved in the provision of medical services as well as the growing experience in the medical field have naturally resulted in a success rate of around $90 \%$ of surgical operations

In addition, $50 \%$ of the physicians interviewed have first practiced medicine abroad and then returned to Lebanon, with $40 \%$ of them currently practicing in more than two countries. In the case where doctors have worked abroad and are familiar with the international standards, their reputation, with information about them being available to patients, appears to significantly contribute to the development of medical tourism in Lebanon. In the second case of doctors practicing both in Lebanon and abroad, patients can be assured of a medical follow-up when they return home.

Figure 2. Evolution of the Number of Dentists and Physicians in Lebanon

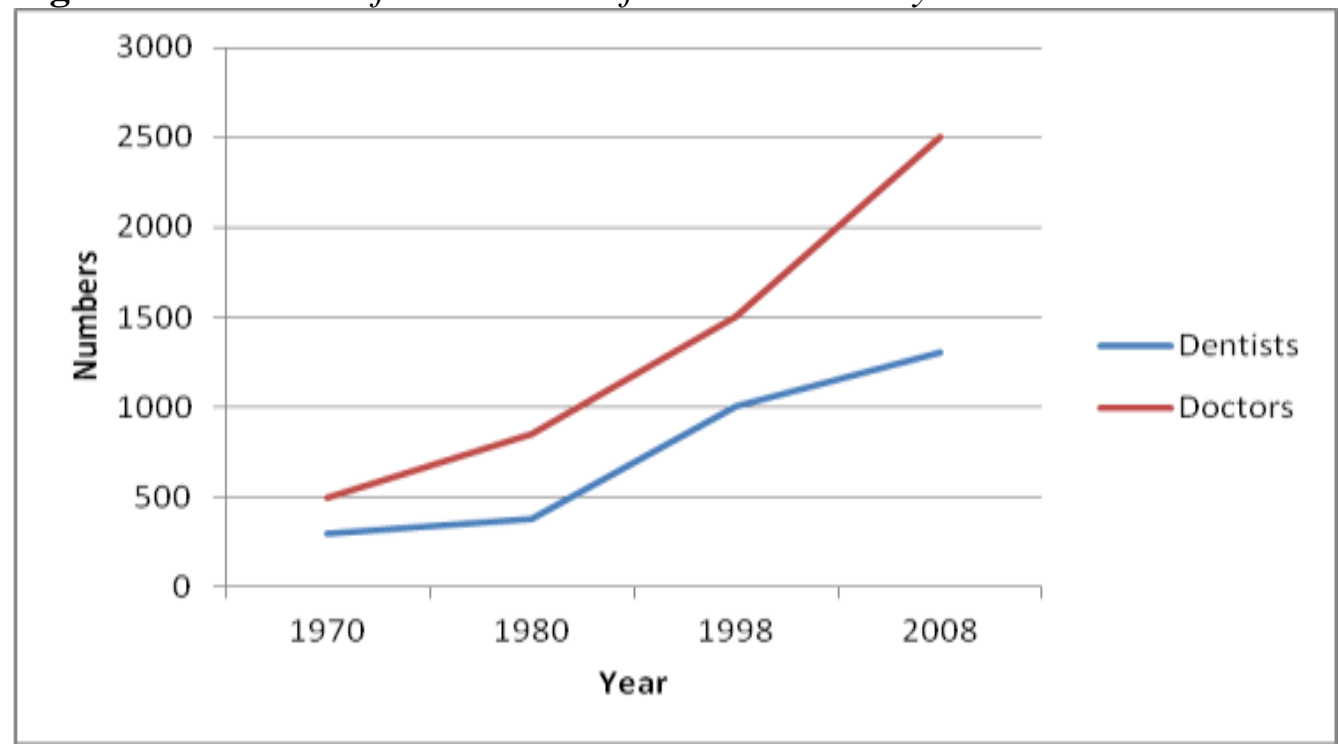

Source: Ministry of Health, 2010.

A comprehensive analysis of the evolution of the medical sector (Figure 2), presenting raw values, shows the very rapid rise that this sector experienced. The number of doctors was over 500 in 1970 and had reached the level of 2,500 by 2008 . Dentists, being stable in number in the 1970 s, rose significantly during the 1980 s. 


\section{Types of Treatment and Price}

According to interviewed physicians and the Ministry of Health, cosmetic and plastic surgery account for the largest share of the medical market in Lebanon. $70 \%$ of medical tourists, especially the ones coming from the Gulf countries, travel to Lebanon seeking this type of treatment.

Medical treatment price competition between the neighboring countries of the region (Dubai, Jordan, Syria and Lebanon) is a very important indicator of the development of medical tourism. Comparisons between the prices of the leading countries are quite informative regarding their attractiveness in the provision of medical care (Chardon 2010, Tounsil 2010). Looking at Figure 3, it is noted that prices for the different types of treatment range between $1,000 \$$ and $4,000 \$$ while the aesthetic surgery prices vary from $2,000 \$$ to $4,000 \$$.

Figure 3. Comparison of Prices Between the Lebanon and other Neighboring Countries in the Region

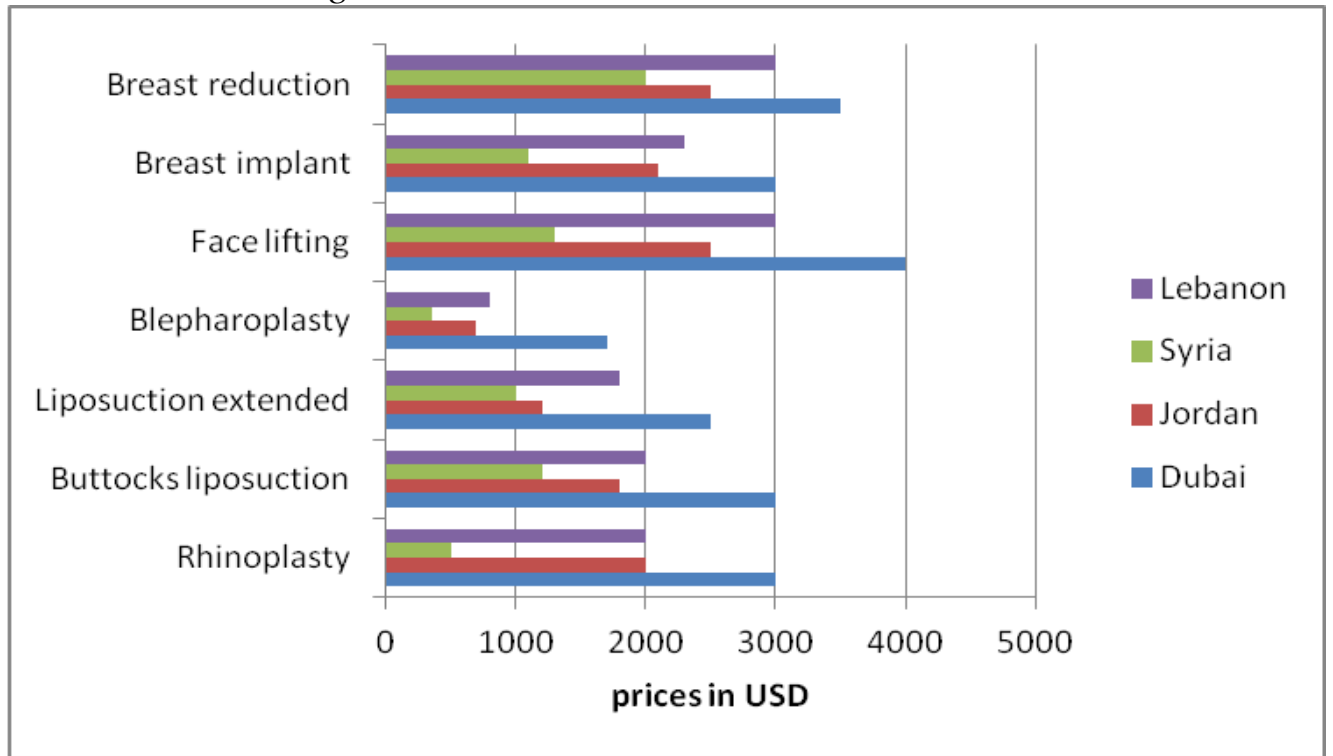

Source: Ministry of Health and Ministry of Tourism, 2011; Personal communication with Doctors.

Medical treatment in Dubai seems to be the most expensive while healthcare services have a comparatively low cost for patients in Syria. On this ground, Jordan appears to be the most competitive country of the region, offering truly competitive prices. The Lebanese Ministry of Tourism, despite its limited resources, has evidently managed to rebuild the image of the country in the eyes of foreign potential customers; a quite demanding task in the socioeconomically and politically unstable climate of the region. The political situation which emerged in the wake of the Arab spring influenced all the countries of the region and ruined their image in the rest of the world. To achieve this goal, the Department followed the strategy of creating a mediaimage of the country based on its diversity, authenticity and specificity on the cultural, historic and natural levels. In the specific area of medical tourism, Lebanon re-gained its attractiveness by allowing patients to receive treatment 
without having to go through tedious, bureaucratic procedures. In addition, tourists visiting Lebanon for health reasons are issued a visa right at the time they arrive at the airport free of charge. Lowering the cost of the whole touristic package is also part of the strategy of attracting medical tourists; a package of services including transportation, accommodation and the treatment deposit is priced at around 2,000\$.

\section{Outflows Analysis}

Outward flows are defined as the number of Lebanese citizens who travel abroad for treatment. Because of the lack of detailed statistics on the Lebanese who get medical treatment abroad, the present analysis is based on data collected by the Ministry of Tourism and the General Security Office for the period 2006-2010. Despite the limitations imposed by the datasets, their analysis is indicative of the evolution of the demand for this type of tourism and the destinations preferred by the Lebanese.

\section{Medical Tourism Outflows}

Table 5 shows that the total numbers of Lebanese medical tourists followed a rising pattern from 2006 to 2009, reaching a maximum level in 2009 (an increase of 2,410,614 individuals). A decline followed this peak with the number of tourists falling to $1,847,582$ in 2010.The number of the Lebanese who sought treatment abroad was $60 \%$ lower than in 2009.

Table 5. Evolution of the Number of Tourists and Lebanese Medical Tourists Abroad

\begin{tabular}{|l|c|c|c|}
\hline & Total tourists & Total medical tourists & \% medical tourists \\
\hline $\mathbf{2 0 0 6}$ & 652,833 & 46,900 & 7.2 \\
\hline $\mathbf{2 0 0 7}$ & $2,383,186$ & 29,821 & 1.3 \\
\hline $\mathbf{2 0 0 8}$ & $2,681,535$ & 39,870 & 1.5 \\
\hline $\mathbf{2 0 0 9}$ & $3,063,447$ & 44,290 & 1.4 \\
\hline $\mathbf{2 0 1 0}$ & $1,847,582$ & 37,510 & 2.0 \\
\hline
\end{tabular}

Source: Ministry of Tourism, 2011.

The comparison between the number of regular tourists and that of medical tourists for the period 2006-2010 shows that the trends were reversed in 2006-2007. In the period between 2008 and 2009, medical tourism follows an increasing trend similar to that of total tourism. From 2009 onwards, the fall begins for all sorts of tourism among the Lebanese people (Figure 4). 
Figure 4. Comparison Between the Number of Tourists and Medical Tourists, 2006-2010

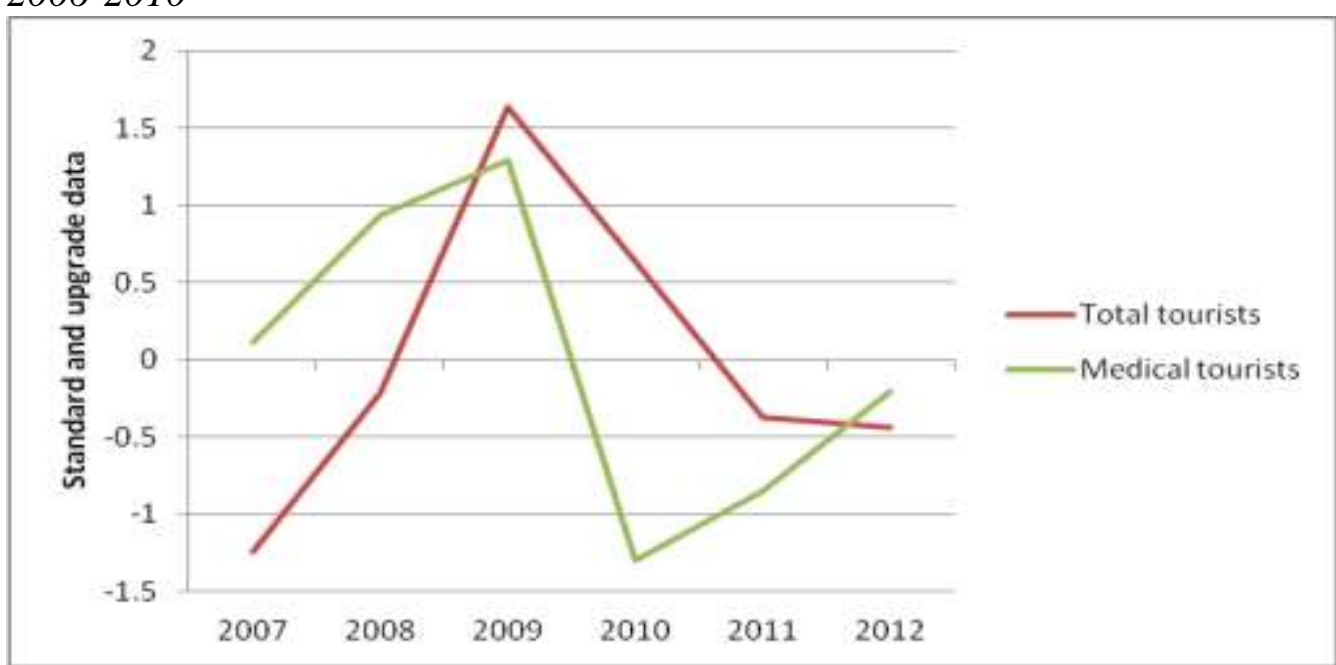

Source: Geography Department USJ, 2014.

\section{Preferred Destinations of the Lebanese Patients}

The present study is mainly concerned about the development of medical tourism practiced by the Lebanese and thus, it attempts to identify the destinations that Lebanese tourists prefer.

According to the analysis of the data on the destinations chosen by the Lebanese medical tourists in the period 2006-2010, Syria is the most preferred destination $(27.77 \%)$ followed by France (14\%) and Jordan (7.05\%). The European country that attracts the majority of Lebanese tourists is France, which is most probably a destination popular among individuals of high socioeconomic background (Table 6).

Table 6. Average Percentages of Preferred Destinations by the Lebanese Medical Tourists

\begin{tabular}{|l|c|}
\hline & Average percentage (2006-2010) \\
\hline Jordan & $7.05 \%$ \\
\hline Syria & $27.77 \%$ \\
\hline Turkey & $0.17 \%$ \\
\hline Tunis & $1.75 \%$ \\
\hline France & $13.92 \%$ \\
\hline Germany & $2.25 \%$ \\
\hline Czech Republic & $1.98 \%$ \\
\hline Hungary & $0.05 \%$ \\
\hline Romania & $0.06 \%$ \\
\hline USA & $3.32 \%$ \\
\hline Canada & $0.86 \%$ \\
\hline Brazil & $0.29 \%$ \\
\hline Others & $40.53 \%$ \\
\hline
\end{tabular}

Source: Ministry of Tourism, 2011. 
Table 7. Spatial Analysis of Outflows (Contribution of Countries which the Lebanese Medical Tourists are Going for Treatment (Calculation Attractiveness))

\begin{tabular}{|l|c|c|c|c|c|}
\hline \multirow{2}{*}{ Jordan } & \multicolumn{5}{|c|}{ Preferential issue } \\
\cline { 2 - 6 } Syria & $\mathbf{2 0 0 6}$ & $\mathbf{2 0 0 7}$ & $\mathbf{2 0 0 8}$ & $\mathbf{2 0 0 9}$ & $\mathbf{2 0 1 0}$ \\
\hline Turkey & 2.914502 & 0.360054 & 0.45612 & 0.381272 & 0.259724 \\
\hline Tunis & 0.483579 & 0.914966 & 1.253088 & 1.120536 & 0.885366 \\
\hline France & 1.281844 & 1.025475 & 0.904718 & 0.542953 & 0.801366 \\
\hline Germany & 0.772148 & 1.270184 & 1.513826 & 0.681376 & 0.321814 \\
\hline Czech Republic & 1.823517 & 0.390848 & 0.804155 & 0.713052 & 0.823635 \\
\hline Hungary & 0.444651 & 0.786993 & 1.270602 & 0.937541 & 1.291504 \\
\hline Romania & 0.275725 & 1.148855 & 1.306828 & 0.973246 & 0.969605 \\
\hline USA & 2.215759 & 0.604298 & 0.71085 & 0.426606 & 0.503716 \\
\hline Canada & 2.147089 & 0.320461 & 0.942414 & 0.678691 & 0.400683 \\
\hline Brazil & 3.192948 & 0.131139 & 0.462114 & 0.362261 & 0.21387 \\
\hline Others & 0.378136 & 0.879797 & 1.681384 & 1.513587 & 0.141839 \\
\hline Sourc: Gog & 3.304754 & 0.26438 & 0.310997 & 0.27996 & 0.165282 \\
\hline & 0.536365 & 0.576919 & 0.998558 & 1.218058 & 1.397433 \\
\hline
\end{tabular}

Source: Geography Department USJ, 2014.

In 2006, a real predominance of the American continent in the preferences of the Lebanese tourists is noted (United States 3.1, Brazil 3.3), followed by Hungary (2.2) and Romania (2.1). In the following year, Lebanese tourists' preferences appear to change in favour of Turkey, Tunisia and the Czech Republic. In 2008, Lebanese tourists mainly travel to the Syria (1.25), Tunisia (1.51), Germany (1.27) and Czech Republic (1.30), with all these countries experiencing a very rapid rise in the inflow of Lebanese patients. In 2009, Syria (1.12) appears to remain in its high position in Lebanese preferences, along with Canada (1.51) which is chosen by an increasing number of people. From 2009 onwards total outflow of medical tourists is decreased irrespective of the destination country. During this period, only Germany manages to keep its inflow of Lebanese medical tourists rather stable. This could be explained by the fact that German clinics often provide numerous special services: low travel costs and hosting facilities for relatives who often accompany the sick from distant countries, easy access to visas, facilitation of travel formalities, easy transfers from the airport to the hospital, adaptation of national cuisine to different food cultures (kosher, halal, or other) (Linden 2011) and provision of interpretation services (Table 7).

\section{Reasons}

From these results, three periods could be identified in the evolution of the demand for medical tourism in Lebanon: a peak in 2006, followed by an increasing trend in the 2007-2009 period and finally, from 2009 onwards, a fall. The examination of the mechanisms driving this evolution and the patterns of the tourism flows during these three periods is considered crucial. 


\section{$\underline{\text { Reasons for Peak }}$}

The political situation in 2006 characterized by the Lebanese-Israeli war, pushed many Lebanese patients to leave the country seeking treatment abroad, thus, providing substantiated explanation for the peak in the medical tourism outflow in that year.

\section{Reasons for Growth (2007-2009)}

The fall of 2007 could be explained by the stability and political security, offering suitable conditions for patients to seek treatment in their country. Furthermore, in 2007, the Lebanese banks proposed a number of reforms facilitating the provision of cosmetic care; for instance, a loan could be reserved for those who wanted to have recourse to cosmetic surgery. The National Bank was the first to make the steps towards the implementation of these reforms. Consequently Lebanon got in the process of facilitating the reception of cosmetic treatment in foreign countries. Additionally, travel agencies offering spa packages (especially to Karlovy in Prague) as well as other non-medical services to boost health based on natural therapeutic sources (thermal springs, gasses, peloids) or alternative techniques such as physical and kinetic treatment, health education and healthy food contributed in the increase in medical tourism outflows in Lebanon. The competitive prices of medical treatment in Lebanon's neighboring countries, especially in Syria, Jordan and the UAE were also a significant determinant of this rise: for example, rhinoplasty in Syria costs $500 \$$ including transportation while in Lebanon it costs between 2,000\$ till 3,000\$.

\section{Reasons for the Fall}

From 2009 onwards, the decline in the number of medical tourists (Figure 4) could be explained by two main reasons. The first is the development of health care in Lebanon, including the opening of specialized clinics in the field of cosmetic surgery, the proliferation of beauty and spa centers and the good reputation of the medical facilities in a large number of specialities (organ transplantation, bone marrow, treatment of epilepsy, 23 centres for cardiac surgery, six centres specializing in renal transplants, twelve centres for radiation therapy, etc.) certainly provided an important incentive to Lebanese patients to seek treatment in their own country (Chardon 2010). The second incidence which resulted in a decline in the outflows from Lebanon was certainly the economic crisis which has shaken Lebanon.

\section{Conclusions}

Analysis of medical tourism inflows based on the statistics obtained from the Lebanese Ministry of Tourism has enabled us to better understand the development of these flows through time. Analysing the inflows by the visitors' countries of origin is proven to be quite explanatory regarding the 
reasons that contribute to this growth in Lebanon, despite the competition from neighboring countries.

According to the analysis of the inflows and tourists' preferences, we found that patients of all the neighboring countries prefer the medical services provided in Lebanon rather than their own countries, with the exception of Syria. The reason certainly lies in the precarious situation of this country. What should be highlighted here is the increase of the Western tourists, especially the ones coming from Germany and the France. Several reasons could explain this trend. The most important among them are the following: the high medical standards of Lebanese health centers, the reputation of Lebanese doctors, the unstable political situation in the neighboring countries, the facilities provided by the Lebanese authorities, the competitive prices and the strategy adopted by the various health-care departments.

Regarding the outflow of Lebanese medical tourists, the three periods identified in the outflow's evolution through time provide the theoretical scheme for explaining the mechanisms driving this evolution. Several reasons could explain the evolution of the outflows. First of all, the political situation in 2006 has highly influence the demand for medical tourism in Lebanon. In this year, Lebanon has been engaged in the Lebanese-Israeli war which interrupted the growth of the Lebanese economy and had catastrophic consequences such as the paralysis of the national airport for several months. In the years that followed the war, the increase in the demand for medical tourism is mainly the outcome of the travel agencies offering packages at competitive prices for treatment in the neighboring countries. The fall in the outflows, taking place from 2009 onwards, could be explained by the development of more care centers and clinics specializing in cosmetic surgeries, the role of the Lebanese public figures in promoting cosmetic Surgery and the rise in the value of EURO against the dollar.

The flows analysis further supports the argument that Lebanon is not only attractive for tourists but that its medical services advancement appears to satisfy also the local population; a fact that is reflected in the decrease in the number of the Lebanese people who choose to travel abroad for medical care after 2009. What should be noted here is that the above conclusions are rather preliminary as they are mainly based on flawed datasets imposing many limitations. However, it is considered that they constitute a significant first step in analysis of the nature and prospects of medical tourism in Lebanon,

In addition to the limitations imposed by the datasets, in the context of the further study, it was impossible to extend our study area including more cities and villages. It might be assumed that Beirut and other Lebanese regions should have experienced a development in medical tourism having the characteristics discussed in the present study. However, to provide strong evidence in favour od this argument would have required a field work which could not be completed in the time-frame of the present study.

Finally, we would have preferred to be able to observe medical tourists not only during their stay but also after their return to the country. In order to achieve that, the active contribution of doctors and medical centres is 
considered to be a significant prerequisite but, taking into account the very delicate subject and the confidentiality of information on medical issues, quite hard to ensure. Not being able to follow patients after receiving their treatment is considered to be one of the major limitations of the present study. Getting the whole picture of how patients perceive the experience of getting treated in Lebanon, would have allowed us to get a deep understanding of the numerous activities related to medical tourism, the post-operative follow-ups, the economic aspect etc.

\section{References}

Bauer I (2008) The health impact of tourism on local and indigenous populations in resource-poor countries. Journal of Travel Medicine and Infectious Disease 6: 276-291.

Boutros E (2010) Le tourisme médical, un potentiel de 1,2 milliards de dollars (Medical tourism, potential of 1.2 billion USD). Retrieved from http://www.baldati.com/news/article.php?articleid=1549. [Accessed: 13 June 2009]

Chardon L (2010) Tourisme médical: les atouts du Liban sont nombreux (The advantages of medical tourism for Lebanon). Journal of Commerce du Levant 5602: 56-69.

Jeevan R (2008) Cosmetic tourism and the burden on the NHS. Journal of Plastic Reconstructive and Aesthetic Surgery 61: 1423-1424.

Linden M (2011) Boom du Tourisme Médical en Allemagne (Boom of Medical Tourism in Germany). Retrieved from http://www.lalibre.be/actu/sciencessante/boom-du-tourisme-medical-en-allemagne-51b8db56e4b0de6db9c3662f. [Accessed: 29 September 2011]

Tounsil R (2010) Tarif Chirurgie Esthétique: un Comparatif France-Tunisie (Cost of Cosmetic Surgery: A Comparative Between France-Tunisia). Retrieved from https://chirurgieaccomplissementtunisie.wordpress.com/2010/11/02/tarifchirurgie esthetique-un-comparatif-france-tunisie/. [Accessed: 2 November 2010]

Vaillant G (2010) Le tourisme médical mis en cause (Medical tourism questioned). Retrieved from http://www.lejdd.fr/Societe/Sante/Actualite/Le-tourisme-medicalmis-en-cause-214610). [Accessed: 18 August 2010] 